\title{
Insight into the Theory of Truth from the Lens of Five Review Articles
}

\author{
Farni Wulandari ${ }^{1}$,Cendy Lauren ${ }^{2}$, and Anggi Resti Rahmadani ${ }^{3}$ \\ ${ }^{1}$ Applied Linguistics Center, Pekanbaru, Indonesia \\ ${ }^{2}$ High School 2 Tambang, Pekanbaru, Indonesia \\ ${ }^{3}$ Vocational High School 3 Pekanbaru, Indonesia \\ farniwulandari@gmail.com
}

\author{
ARTICLE HISTORY \\ Received : 1 April 2019 \\ Revised : 17 April 2019 \\ Accepted : 27 May 2019
}

\section{KEYWORDS}

Truth

Critique

Linguistics Theory

Difference of Perspectives

Meaning

\begin{abstract}
As a central philosophical subject, the discourse of truth has existed for thousands of years. One of the most influential theories of truth is James \& Katz (1975) book entitled "The Meaning of Truth." This study aims to analyze the different views on the theory of truth from five articles that have reviewed the theory. This study used a descriptive qualitative method to review these five articles, which serve as the data that this study analyzed. The textual analysis identified and classified the different opinions of other researchers who have reviewed the theory in detail. Additionally, this paper also reviewed the strengths and weaknesses of these five review articles that served as a benchmark in reviewing the theory of truth.
\end{abstract}

\section{Introduction}

Researchers have theorized the matter of truth for a millennium, that it is almost impossible to cover the wholesome nuance of truth in one booklet alone one article. Words held many meanings in whatever form they take the appearance of (Derin et al., 2019). What makes words so much more interesting is that context makes the truth of word meanings very different from first glance, even when it is written in seemingly plain terms (Bates, Lane, \& Lange, 1993; Englebretsen, 2017). The theme of a writing piece can significantly change the meaning of the words it contains (Davidson, 2000; Fischer, Halbach, Kriener, \& Stern, 2015).

The branch of science that studies the meaning of words is known as semantics. Kamp (1981) has explained meaning as two different concepts that dominate semantics. The first is how meaning is seen as the determiner of truth. The second is how meaning is what a language user obtains when they understand the words that they see or hear. These two concepts have influenced many disciplines, including the field of education (Kendler, 2015). With this in mind, this study is interested in a particular psychologist's conception of truth. To be specific, the Harvard Medical School graduate, William James, who is primarily known for his publications on 'truth'.

In this article, a lot of controversies that makes many people interested in reviewing the theory developed by a figure known as the father of this psychologist. This time the author uses a qualitative descriptive method to review at least five articles that have been reviewed by several authors to find out what theorists are more definite about the truth stated by William James.
This writing is also motivated by the problems developed in writing articles that serve as a benchmark in writing this article. In writing this article, the writer develops the strengths and weaknesses of the articles that are reviewed by several authors in other articles that serve as a benchmark in writing this article.

In a famous article, James put forward a theory of truth, but unlike Peirce's argument, discusses the practical role used by the concept of truth. James also asserted truth represented belief: true belief is a satisfying belief, in a certain sense.

However, unlike Peirce James suggested that what can be satisfying cannot be released and cannot be forced, namely: how they will discuss and investigate what is going on. In a lecture published as "Pragmatism New Names for Some Old Ways of Thinking: A New Name for Some Old Ways of Thinking" (1907), James wrote:

\footnotetext{
"Ideas ... become true just in so far as they help us get into satisfactory relations with other parts of our experience, to summarize them and get about them by conceptual short-cuts instead of following the constant succession of particular phenomena."
}

James \& Katz (1975: 34).

In The Meaning of Truth, he multiplies by quoting a lot and noting that "when pragmatists speak of truth, they and their ideas, namely their workability" (James \& Katz, 1975: 6). James's point is that from a practical point of view, we use the concept of truth to signal our belief in certain ideas or beliefs. True beliefs are actionable beliefs, which are reliable, and that lead to predictable results. Further speculation is the disturbance that is not any good. 


\section{Method}

This method of this study is a qualitative description. This is chosen because of its ease of enabling researchers to simultaneously collect data and analyze said data. This method is used to look at the five articles that have reviewed the theory of truth that William James conceptualized.

These five articles are then analyzed with textual analysis, which is a methodology that lets researchers interpret the language in the text. This analysis method is chosen in order to gain information regarding how the authors of each article view James' theory of truth.

\section{Results \& Discussion}

In his 1907 book Pragmatism, James described empirically, nominalist, positivist and utilitarian inspiration of his pragmatic philosophy, which in many places in his works he described as radical empiricism: "Pragmatism represents a very familiar attitude in philosophy, empirical attitude, but according to his I, that represents it, both in a more radical form and in a less pleasant form than he had ever assumed.

A pragmatist turns his back firmly and again because of many habits that are favoured by professional philosophers. He turned away from abstraction and shortcomings, from verbal solutions, from a priori terrible reasons, from fixed principles, closed systems, and absolute presence and origin He turned to concreteness and adequacy, towards facts, towards actions and power. That means an obedient empirical temperament and a rationalist temper to give up sincerely.

For example, agreeing with nominalism, always appealing to special things; with utilitarianism in emphasizing the practical aspects; with positivism in contempt of verbal solutions, useless questions and metaphysical abstractions. There has not been a specific result, so far, but only an attitude of orientation is what the pragmatic method means. The attitude of looking away from the first things, principles, 'categories,' supposed necessities; and of looking towards last things, fruits, consequences, facts.

Regarding James's pragmatic truth theory, Frank Thilly and Ledger Wood wrote: "Pragmatism is a method of determining the truth or falsity of propositions that are appropriate because they fulfil or do not meet our goals and meet our biological and emotional needs; the true proposition is the acceptance that leads to success, the wrong proposition is the proposition that results in failure and frustration.

In introducing a reference to satisfaction, usefulness, practicality and role in the definition of truth, James drastically changed the pattern of pragmatism from Pierce's more intellectual formulation. "The test, then, of a theory, a belief, a doctrine, must affect us, its practical consequences.
This is a pragmatic test. Always ask yourself what the difference will be in your experience whether you accept materialism or idealism, determinism or free will, monism or pluralism, atheism or theism.

On the one hand, it is the doctrine of despair; on the other hand, the doctrine of hope. 'Regarding pragmatic principles, if God's hypothesis works satisfactorily, in the broadest sense of the word, that is true.

'Test of truth, then, that is the practical consequence; ownership of truth is not an end in itself, but only an initial means for other vital satisfaction. Knowledge is an instrument; it exists for life, not a life for knowledge.

In the famous pragmatic words, the advocate of humanism FCS Schiller: "Pragmatism writes essays to trace the actual 'making of truth', the actual ways in which discrimination between right and wrong is done, and stems from generalizations about methods of determining nature truth.

From such empirical observations, the doctrine is obtained that when a statement claims the truth, the consequences are always used to test its claim.

For pragmatism, "truth" is not permanent, necessary, universal, objective or absolute; on the contrary, "truth," for pragmatists, is basically relative, special, temporary, changeable, subjective.

In pragmatism, the understanding of any proposition, and therefore its truth or falsity, must be judged by the mental habits it causes, the effect it has on the action, and the pragmatic value or work. In pragmatism, the truth or the value of knowledge of a particular proposition has no insight that should give us into things, but rather its beneficial relationship with human life.

Therefore, a pragmatic insult to traditional metaphysics or ontology. For pragmatists, religious beliefs, like all beliefs, have truth values in their level of use for human life and well-being. Therefore, pragmatism is more than a method; instead, it is a doctrine, theory of knowledge or a kind of epistemology, philosophy.

In the pragmatic world, if individual judgments, or assumptions, or axioms, or postulates, or theories, or systems of thought "work," and meet our psychological, emotional, or social needs, then, to the extent and so long as this applies, it is useful, valuable, and "right." James wrote in his Pragmatism: "True ideas are ideas that we can assimilate, validate, strengthen, and verify.

James argues that "every idea that will bring us to prosper from one part of our experience to another, connect things satisfactorily, work safely, save the workforce, is true to so many, true in so far, true in terms of instrumental. For James, "an idea is not just a mirror or passive reflection of reality; it is a habit of acting in a certain way, and because it is a plan or guide for our actions. If we follow 
this plan, we will have a series of experiences that lead to reality or not.

For example, our ideas about tigers encourage us to take certain actions that can bring us before tigers or not. If these experiences bring us to reality, the idea that drives them is accurate, if they fail to do it, then it's wrong. In short, the idea is correct if it leads us to the object.

The series of experiences that connect ideas with reality is the stable relationship of agreement or appointment. Therefore, for James, truth is not an unchanging or inherent property of an idea; it is something that happens to an idea when verified by experience. There is no truth to something that we find in reality as if it were there before we thought about it.

We make the truth by formulating ideas and acting on them; the verification process (as the word indicates) is indeed one of 'truthmaking.

Bergson placed his finger on the essential nature of truth in James's philosophy when he wrote: 'We find the truth to use reality when we create mechanical devices to use natural force.

It seems to me that we can deduce the whole essence of the pragmatic truth perception in a formula like this: while in other doctrines, new truths are inventions because pragmatism is an invention.

Although James insisted that it was one of humanity's principal tasks to pursue original ideas, he did not regard their ownership as an end in itself, but only as an 'initial means towards other vital satisfaction.

Therefore, there are two aspects to a correct idea: factual verification, and its usefulness for life. These can be distinguished but not separated; unless we have a need or desire for an object, we will not be led to verify our ideas about an object. If we are not interested in tigers, we will not be asked to move actions that will bring us before them.

Ideas are nothing but instruments to satisfy some wants or needs, and verification inexperience is not an end in itself but a process that is fulfilled only in its actual use.

Because individuals differ in their needs and desires, it can be understood that James's pragmatism must emphasize the role of the individual in determining the truth. An idea is right to the extent that it is satisfying, but what satisfies one person does not always satisfy another. Therefore truth is to some degree plastic and relative to individuals.

Explaining the practical, anti-speculative, practical, consequentialism of pragmatism, Juan Jose Sanguineti writes: "Pragmatism is a philosophy that reduces the value of theoretical truth to its practical consequences.

In theory or speculation is knowledge intended to the extent that it shows what is; on the contrary, practical truth shows what must be done. For realism, the main foundation of action is found like things, because things go that far.
In pragmatism, there is no theoretical truth, in the sense that there is no truth that indicates existence: truth is reduced to the human conception that serves action (theory as a function of praxis).

So it is clear that pragmatism is a consequence of every doctrine in which the idea of truth disappears, such as scepticism or even idealism, because if human thought is not a reflection of reality, then it will need to establish a function in that context. Human behaviour: thinking must at least be beneficial to human life.

Then, criticizing the pragmatic theory of James's truth rooted in its practical use, Sanguineti notes it is true that practice can function as verification or sign of truth, but only relates to practical truth: new commercial products show themselves useful in practice; instead, the phrase 'Emperor is emperor' is true or false without practical consequences, James's theory bases itself on several principles regarding what is practical. This principle has become the object of theoretical affirmation.

If not, how do people know whether the idea is practical? (each person may have a very different concept, in this case, it is true that only with high confidence and conviction can one act efficaciously, but confidence is usually born from an awareness of the truth (doctor heals illness with certain medicines that he believes in). Only in exceptional cases do new hypotheses that need to have faith risk the rejection of reality.

P. Coffey's criticism of the Pragmatic Criteria of Utility in relation to Truth: "We do not deny that the practical problems of a belief can create assumptions for or against its truth, that the 'fruits' of doctrine can be criteria. , an additional test, of its truth or falsity, its practical fruits: because of course if false speculative conclusions follow logically from any doctrine as antecedents, this is a certain index whose doctrine is wrong.

Pragmatism Criticism Joseph T. Barron: "Pragmatism Awareness Theory is wrong. This school regards experience as a continuous stream from which the mind chooses certain aspects because of their usefulness or ability to serve.

The mind is basically selective. The mind is not required by the presentation of experience to choose this or that aspect. This is basically free in carrying out its preferences. But does introspection support this opinion? When we examine the way in which our knowledge is formed, is it not clear that our environment often forces knowledge on us, in the sense that we feel ourselves under duress as we know it? Isn't it equally clear that very often we are forced to realize the reality that is contrary to our needs? And which prevents our desires? If our knowledge is true, shouldn't we adjust our judgments about reality with the reality that we value? If introspection decisions are credible, the basic notes in the doctrine of pragmatic knowledge are not based on facts. 
"Knowledge Is Not Completely Practical. Recognizing that knowledge is the result of the interaction of the mind with its environment, the deduction that knowledge never goes beyond the practice field is haram. In essence, it is an undue limitation of the scope of cognitive interest.

Knowledge, which is considered either phylogenetic or ontogenetically, may emerge as a practical interest, but that is not a guarantee for the statement that it must remain practical. Pragmatism emphasizes aspects of thinking that are too important. The falsity of its position is due to the mistaken assumption that a creature can only function within the limits of the cause that makes it exist.

Once a creature has been realized, it can develop new needs that go beyond the causes that produce them. The mind may be practical in the beginning but introspection tells us that it is beyond its practical beginning. When man starts thinking he becomes a thinking creature, and thus he is released from having to limit his thinking to facts that are of practical interest. 'Humans no longer only need to live; they also need to know. Humans start thinking about eating; he has evolved to the point where he eats so he can think.

Knowledge is scientific or contemplative and practical because the world can be understood as well as plastic. We all feel within us the urge to know it merely to know. Curiosity, a disc species of divine discontent, 'drives us to acquire knowledge, many of which are entirely impractical.

Thinking is a means to an end, but it can be a goal in itself. The pleasure that comes from knowledge is one of the values that enrich life for us, and therefore contemplative thinking is not always otiose.

Uninterested contemplation and enjoyment of the beauty, splendour, meaning, and order of things for their interests are for some humans who inherently have a proper function of consciousness.

"A brief discussion of the pragmatic doctrine of the nature of knowledge cannot be ignored without mentioning this school's reproachful attitude towards metaphysical reasoning, and towards speculative philosophy in general."

Pragmatists oppose abstract speculation which states that it is futile and barren. They argue that philosophy must be applied. It must come down from the clouds and become a pedestrian. It must be busy by itself in answering pressing social problems that demand solutions.

This is an attitude of mind that is found not only among people who tend to be pragmatic - it is also found among scientists. Although widely accepted, this view cannot be maintained. "The main reason for prohibiting acceptance is because it is too exclusive.

Philosophy must be practical - but should it be limited to that domain? A more comprehensive and truer view of the function of philosophy includes its speculative and practical functions. It should be noted that in constructing his views on the instrumental character of our thinking,
Dewey has created a speculative philosophy. He proved that the mind must not be speculative with speculation.

The practical value of his speculation 'seems best at best only the negative value of cleansing is considered a mental obstacle to change and to rebuild, and because of its own metaphysical peculiarity is far less clear and provokes doubt than the practical attitude intended to provide it.

A foundation, they tend to weaken, instead of increasing the possible influence for the good that philosophy might have. It can be said that those who deny the validity of metaphysical and speculative thinking do so at the risk of self-contradiction because their statement that metaphysical thought is nugatory itself is metaphysical itself

\section{Conclusion}

James (1907) understands this principle as telling us what practical value truth has. True beliefs are guaranteed not to conflict with subsequent experience. Likewise, Peirce's slogan tells us those true beliefs will remain settled at the end of the prolonged inquiry. Peirce's slogan is perhaps most typically associated with pragmatist views of truth, so we might take it to be our canonical neoclassical theory. However, contemporary literature does not seem to have firmly settled upon a received 'neo-classical' pragmatist theory.

In her reconstruction, Haack (1976) notes that the pragmatists' views on truth also make room for the idea that truth involves a kind of correspondence, insofar as the scientific method of inquiry is answerable to some independent world. Peirce, for instance, does not reject a correspondence theory outright; instead, he complains that it provides merely a 'nominal' or 'transcendental' definition of truth, which is cut off from practical matters of experience, belief, and doubt.

This realisation marks an essential difference between the pragmatist theories and the coherence theory we just considered. Even so, pragmatist theories also have an affinity with coherence theories, insofar as we expect the end of inquiry to be a coherent system of beliefs. As Haack also notes, James maintains an important verificationist idea: truth is what is verifiable.

\section{References}

Bates, L., Lane, J., \& Lange, E. (1993). Writing clearly: Responding to student writing. Boston: Heinie.

Davidson, D. (2000). A coherence theory of truth and knowledge. Epistemology: an anthology, 154-163.

Derin, T., Deliani, S., Fauziah, N., Afifah, N., \& Hamuddin, B. (2019). Indonesians' Tendency to Refer Abbreviation as Acronym: Types of Abbreviation as Word Formation Process. Globish: An EnglishIndonesian Journal for English, Education, and Culture, 8(2). 
Englebretsen, G. (2017). Bare facts and naked truths: A new correspondence theory of truth. Routledge.

Fischer, M., Halbach, V., Kriener, J., \& Stern, J. (2015). Axiomatizing semantic theories of truth?. The Review of Symbolic Logic, 8(2), 257-278.

Haack, S. (1976). The pragmatist theory of truth. The British Journal for the Philosophy of Science, 27(3), 231-249.

James, W. (1907). Pragmatism's conception of truth. The Journal of Philosophy, Psychology and Scientific Methods, 4(6), 141-155.

James, W., \& Katz, E. (1975). The meaning of truth (Vol. 2). Harvard University Press.

Kamp, H. (1981). A theory of truth and semantic representation. Formal semantics-the essential readings, 189-222.

Kendler, K. S. (2015). Toward a limited realism for psychiatric nosology based on the coherence theory of truth. Psychological medicine, 45(6), 1115-1118.

Kirkham, R. L. (1992). Theories of truth: A critical introduction.

Szuchman, L. T., \& Thomlison, B. (2010). Writing with style: APA style for social work. Cengage Learning. 